\title{
Phytochemical Analysis of Tasmannia lanceolata Extracts and Inhibition of Giardia duodenalis Proliferation
}

\author{
Paran Rayan ${ }^{1,2}$, Ben Matthews ${ }^{3}$, Pauline Mc Donnell ${ }^{2}$, Ian Edwin Cock ${ }^{1,2^{*}}$ \\ 'Environmental Futures Research Institute, Nathan Campus, Griffith University, 170 Kessels Rd, Nathan, Queensland 4111, AUSTRALIA. \\ ${ }^{2}$ School of Natural Sciences, Nathan Campus, Griffith University, 170 Kessels Rd, Nathan, Queensland 4111, AUSTRALIA. \\ SSmartwaters Research Centre, Griffith University, Gold Coast, AUSTRALIA.
}

\begin{abstract}
Background: Giardiasis is a debilitating disease caused by gastrointestinal parasites of the genus Giardia. Tasmannia lanceolata (Tasmanian pepper berry) has a high anti-oxidant capacity and has documented therapeutic properties for a variety of pathogenic diseases. Materials and methods: Solvent extracts of $T$. lanceolata berry and leaf were investigated for the ability to block $G$. duodenalis growth. The $I_{50}$ values of the extracts which displayed inhibitory activity were determined to quantify and compare their efficacies. Toxicity was determined using the Artemia franciscana nauplii bioassay. Active extracts were analysed by non-targeted HPLC-OTOF mass spectroscopy (with screening against 3 compound databases) for the identification and characterisation of individual components in crude plant extracts. Results: Methanolic, aqueous and ethyl acetate T. lanceolata berry and leaf extracts displayed potent $G$. duodenalis growth inhibitory activity. The methanolic extracts were the most potent growth inhibitors with $I_{50}$ values of approximately $180 \mu \mathrm{g} / \mathrm{ml}$ and $420 \mu \mathrm{g} / \mathrm{ml}$ for the berry and leaf methanolic extracts respectively. The aqueous, ethyl acetate, chloroform and hexane extracts also inhibited $G$. duodenalis growth, albeit with lower potency. HPLC-QTOF mass spectroscopy analysis of the extracts
\end{abstract}

identified 45 compounds which were present in all T. lanceolata berry extracts. Forty of these were putatively identified by screening against 3 compound databases. All T. lanceolata berry and leaf extracts were nontoxic in the Artemia fransiscana bioassay. Conclusion: The low toxicity of the $T$. lanceolata extracts and their potent $G$. duodenalis growth inhibitory bioactivity indicates their potential as medicinal agents in the treatment and prevention of this disease.

Key words: Anti-Giardial activity, Anti-oxidant, Complementary, Alternative therapies, Gastrointestinal parasite, Giardisis, Tasmanian pepper.

Corresponding author: Dr. Ian Edwin Cock,

Environmental Futures Research Institute, School of Natural Sciences, Nathan Campus, Griffith University, 170 Kessels Rd, Nathan,

Queensland 4111, AUSTRALIA.

Tel no.: +61 737357637 ; Fax no: +61 737355282.

Email: I.Cock@griffith.edu.au

DOI : 10.5530/pj.2016.3.19

\section{INTRODUCTION}

Giardia duodenalis is a protozoal, intestinal parasite that is a common aetiological agent of infectious diarrhoea in humans and is especially associated with childhood morbidity, worldwide. According to World Health Organisation surveillance data, G. duodenalis (syn. G. intestinalis, G. lamblia) is one of the most neglected protozoal gastrointestinal diseases in humans with over 280 million cases of giardiasis reported worldwide per annum. ${ }^{1,2}$ Acute infection, which is known as giardiasis, is endemic to many countries, particularly those with poor socio-economic conditions, inadequate sanitation, untreated water supplies and poor dietary status. ${ }^{3}$ Giardiasis has also been recorded in many other animal species, including domestic pets (cats and dogs). ${ }^{4}$ From a zoonotic perspective, there is notable concern that G. Duodenalis infections in companion animals, lifestock and wild fauna may constitute sources for transmission to humans. ${ }^{4}$

One important issue for public health, land-use and water management professionals is the possible development of a reservoir of Giardia infection within the environment. Evidence suggests that this reservoir of infection has the potential to intermittently re-infect community drinking water supplies. Therefore, effective long-term management schemes to meet and maintain water quality standards ultimately depend on a comprehensive understanding of the sources of water contamination, reliable screening methods, and the ability to provide a variety of appropriate and alternative prevention and treatment strategies. ${ }^{5}$

Chemotherapeutic intervention presently offers a limited range of drugs and these are usually only employed after clinical diagnosis. Moreover, these drugs are ineffective against the infectious cysts, can produce unpleasant side effects, and are expensive with limited availability in developing countries. Frequent reports of drug toxicity, treatment failure and parasite drug resistance have, in some instances, also resulted in an increasing reluctance to over-prescribe synthetic anti-microbials. Despite some promising studies, there are no definitive chemoprophylactic, preventative treatments or vaccine for human giardiasis to date. Chemotherapeutic intervention for acutely infected individuals and chronic human and animal carriers has been recommended as a preventative strategy to limit infection transmission and to reduce endemic resurgence.However, only a narrow range of drugs are available. Such drugs include quinacrine, furazolidone, paromycin, the benzimidazoles and the nitroimidazoles. ${ }^{6}$

Metronidazole is currently still the drug of choice, although this is only effective against the trophozoite stage of the parasite, whilst the viable infectious cysts continue to be excreted into the environment. Furthermore, metronidazole and most other anti-giardial drugs produce unpleasant side effects, such as nausea, vertigo, anorexia, vomiting, diarrhoea, and hallucinations. ${ }^{7,8}$ Drug toxicity with metronidazole therapy has also been widely reported. ${ }^{9}$ The benzimidazoles (albendazole, mebendazole) seem to have lower incidences of adverse side effects compared to other anti-giardial drugs, but these drugs are relatively expensive and not as readily available in many developing countries where giardiasis is most prevalent. ${ }^{6,9}$ There have also been increasing reports of treatment failure using the nitroimidazoles and benzimidazoles, and drug resistance by the organism is now a major rising concern. ${ }^{6,7}$ Interestingly, from a social perspective, there also appears to be an increasing reluctance towards the use (or over-use) of synthetic anti-microbial drugs in disease treatment and prevention. ${ }^{10}$ In more recent years, the introduction of new 
and more effective agents has improved the overall chemotherapy for a number of parasitic diseases. However, the pharmaceutical industry is still plagued by numerous problems, including the ongoing development of resistance by infectious organisms to therapeutic agents and the limited repertoire of compounds available.

Therefore, one of the greatest challenges for public, rural, and medical health professionals involved in the control of giardiasis and other parasitic diseases is finding novel, safe, cost-effective drug alternatives. Recent studies have begun to re-examine the use of complementary and alternative therapies including plant extracts used in traditional healing systems, ${ }^{11}$ essential oils, ${ }^{12,13}$ and functional foods such as saturated fatty acid rich coconut milk ${ }^{14}$ to treat giardiasis.

Tasmannia lanceolata (commonly known as Tasmanian pepper or mountain pepper) is a shrub which is endemic to the woodlands and cool temperate rainforests of Tasmania and the south-eastern region of the Australian mainland. ${ }^{15}$ It is a medium to large shrub that varies between 2-5 $\mathrm{m}$ in height. Individual plants are unisexual, having either male or female flowers. The stems, branches and twigs are red in colour. The aromatic leaves are lanceolate to narrowly elliptical in shape $(4-12 \mathrm{~cm}$ long, $0.7-2 \mathrm{~cm}$ wide) with a distinctly pale under surface. Small creamywhite unisexual flowers appear during the summer months. These develop into small fleshy black 2 lobed berries (5-8 $\mathrm{mm}$ wide) during autumn.

The berries, leaves and bark of this species have historical uses as a food and as a medicinal plant. ${ }^{16}$ When the berry is air dried it forms a small, hard peppercorn which is suitable for milling or crushing. The berry has a pleasant spicy flavour and sharp aroma. T. lanceolata was used as flavouring agent by Australian Aborigines and more recently by European settlers. Historically, the leaves have been used as a herb and the berries have been used as a spice. Australian Aborigines also used T. lanceolata as a therapeutic agent to treat stomach disorders and as an emetic, as well as general usage as a tonic. ${ }^{16}$ Reports also exist of the use of T. lanceolata by Australian Aborigines for the treatment and cure of skin disorders, venereal diseases, colic, stomach ache and as a quinine substitute. ${ }^{16}$ Later, European colonists also recognized the therapeutic potential of T. lanceolata and the bark was used as a common substitute for other herbal remedies (including those derived from the related South American Winteraceae species, Drimys wintera (winter bark) ${ }^{17}$ to treat scurvy due to its high anti-oxidant content. ${ }^{16,18}$

Despite its ethnobotanical usage, until recently there have been limited rigorous scientific studies into the therapeutic properties of $T$. lanceolata. Recent studies have demonstrated the high anti-oxidant content of T. lanceolata fruit and leaves. ${ }^{18}$ It has been postulated that this high anti-oxidant content may provide therapeutic effects for this plant. ${ }^{15}$ Indeed, studies within our laboratory have reported potent inhibition of bacterial growth by T. lanceolata berries, leaves and peppercorns. ${ }^{19}$ However, despite the documented ability of $T$. lanceolata to inhibit prokaryotic cell growth, similar studies against eukaryotic infective agents are lacking. The current study was undertaken to test T. lanceolata leaf and berry extracts for the ability to inhibit the growth of the gastrointestinal parasite G. duodenalis.

\section{MATERIALS AND METHODS}

\section{T. lanceolata samples}

Dried T. lanceolata berry (without seed) and leaf materials were purchased from GoWild Harvest, Australia. The material was stored at $-30^{\circ} \mathrm{C}$ until use. The plant materials were thawed and freshly ground to a coarse powder prior to extraction. Individual $1 \mathrm{~g}$ quantities of the ground plant materials were prepared by weighing each plant part into each of 5 tubes and adding $50 \mathrm{ml}$ of methanol, water, ethyl acetate, chloroform or hexane respectively. All solvents were obtained from Ajax and were AR grade. The berry and leaf material was extracted in each solvent for $24 \mathrm{~h}$ at $4^{\circ} \mathrm{C}$ with gentle shaking. The extracts were filtered through filter paper (Whatman No. 54) under vacuum followed by drying by rotary evaporation in an Eppendorf concentrator 5301. The resultant dry extracts were weighed and redissolved in $10 \mathrm{ml}$ deionised water (containing 1\% DMSO).

\section{Qualitative phytochemical studies}

Phytochemical analysis of the T. lanceolata extracts for the presence of saponins, phenolic compounds, flavonoids, polysteroids, triterpenoids, cardiac glycosides, anthraquinones, tannins and alkaloids was conducted by previously described assays. ${ }^{20,21}$

\section{Inhibitory bioactivity against Giardia duodenalis trophozoites}

\section{Parasite culture}

The Giardia duodenalis S-2 (sheep strain 2) trophozoite strain used in this study were previously supplied by Professor Andre Buret, University of Calgary, Canada. G. duodenalis tropozoites were maintained and subcultured anaerobically at $37^{\circ} \mathrm{C}$ in TYI-S-33 growth media supplemented with $1 \%$ bovine bile (Sigma), 10\% Serum Supreme (Cambrex Bioproducts) and $200 \mathrm{IU} / \mathrm{ml}$ penicillin $/ 200 \mu \mathrm{g} / \mathrm{ml}$ streptomycin (Invitrogen, USA). Confluent mid log phase cultures were passaged every 2 days by chilling the cultures on ice for a minimum of $10 \mathrm{~min}$, followed by vortexing to dislodge the adherent trophozoites from the walls of the culture vessel. Fresh culture media $(5 \mathrm{ml})$ was seeded with approximately $1 \times 10^{5}$ trophozoites for each passage.

\section{Evaluation of anti-Giardial activity by direct parasite enumeration}

Anti-Giardial activity of the extracts was also assessed by direct enumeration of parasite numbers in the presence or absence of extracts. ${ }^{20}$ For each test, aliquots of the trophozoite suspension $(70 \mu \mathrm{l})$ containing approximately $1 \times 10^{5}$ trophozoites were added to the wells of a 96 well plate. A volume of $30 \mu \mathrm{l}$ of the test extracts or the vehicle solvent or culture media (for the negative controls), or metronidazole (for the positive control) was added to individual wells and the plates were incubated anaerobically at $37^{\circ} \mathrm{C}$ for $6 \mathrm{~h}$ in a humidified anaerobic atmosphere. Following the $6 \mathrm{~h}$ incubation, all tubes were placed on ice for a minimum of $10 \mathrm{~min}$, followed by vortexing to dislodge the adherent trophozoites from the walls of the culture vessel. The suspensions were mounted onto a Neubauer haemocytometer (Weber, UK) and the total trophozoites per $\mathrm{ml}$ and trophozoite viability were determined. All assays were performed in triplicate. The anti-proliferative activity of the test extracts was determined and expressed as a \% of the untreated control trophozoites per ml.

\section{Determination of $\mathrm{IC}_{50}$ values against Giardial trophozoites}

For $\mathrm{IC}_{50}$ determinations, the plant extracts were tested across a range of concentrations. The assays were performed as outlined above and graphs of the $\%$ of untreated Giardial growth versus concentration were plotted for each extract. Linear regression was used to calculate the $\mathrm{IC}_{50}$ values.

\section{Toxicity screening \\ Reference toxin for toxicity screening}

Potassium dichromate $\left(\mathrm{K}_{2} \mathrm{Cr}_{2} \mathrm{O}_{7}\right)$ (AR grade, Chem-Supply, Australia) was prepared as a $1.6 \mathrm{mg} / \mathrm{ml}$ solution in distilled water and was serially diluted in artificial seawater for use in the Artemia franciscana nauplii bioassay. 


\section{Artemia franciscana nauplii toxicity screening}

Toxicity was tested using a modified Artemia franciscana nauplii lethality assay. ${ }^{22,23}$ Briefly, $400 \mu \mathrm{l}$ of seawater containing approximately 46 (mean $46.8, \mathrm{n}=148, \mathrm{SD} 13.6)$ A. franciscana nauplii were added to wells of a 48 well plate and immediately used for bioassay. A volume of $400 \mu \mathrm{l}$ of diluted plant extracts or the reference toxin were transferred to the wells and incubated at $25 \pm 1^{\circ} \mathrm{C}$ under artificial light (1000 Lux). A negative control $(400 \mu$ l seawater) was run in triplicate for each plate. All treatments were performed in at least triplicate. The wells were checked at regular intervals and the number of dead counted. The nauplii were considered dead if no movement of the appendages was observed within 10 sec. After $72 \mathrm{~h}$ all nauplii were sacrificed and counted to determine the total \% mortality per well. The $\mathrm{LC}_{50}$ with $95 \%$ confidence limits for each treatment was calculated using probit analysis.

\section{Non-biased HPLC-MS quadrapole time-of-flight QTOF analysis}

Chromatographic separations were performed using $2 \mu \mathrm{L}$ injections of sample onto an Agilent 1290 HPLC system fitted with a Zorbax Eclipse plus C18 column $(2.1 \times 100 \mathrm{~mm}, 1.8 \mu \mathrm{m}$ particle size $)$. The mobile phases consisted of (A) ultrapure water and (B) 95:5 acetonitrile/water at a flow rate of $0.7 \mathrm{~mL} / \mathrm{min}$. Both mobile phases were modified with $0.1 \%(\mathrm{v} / \mathrm{v})$ glacial acetic acid for mass spectrometry analysis in positive mode and with $5 \mathrm{mM}$ ammonium acetate for analysis in negative mode. The chromatographic conditions utilised for the study consisted of the first $5 \mathrm{~min}$ run isocratically at $5 \% \mathrm{~B}$, a gradient of (B) from $5 \%$ to $100 \%$ was applied from $5 \mathrm{~min}$ to $30 \mathrm{~min}$, followed by $3 \mathrm{~min}$ isocratically at $100 \%$. Mass spectrometry analysis was performed on an Agilent 6530 quadrapole time-of-flight (QTOF) spectrometer fitted with a Jetstream electrospray ionisation source in both positive and negative mode.

Data was analysed using the Masshunter Qualitative analysis software package (Agilent Technologies). Blanks using each of the solvent extraction systems were analysed using the Find by Molecular Feature algorithm in the software package to generate a compound list of mole- cules with abundances greater than 10,000 counts. This was then used as an exclusion list to eliminate background contaminant compounds from the analysis of the extracts. Each extract was then analysed using the same parameters using the Find by Molecular Feature function to generate a putative list of compounds in the extracts. Compound lists were then screened against three accurate mass databases; a database of known plant compounds of therapeutic importance generated specifically for this study (650 compounds); the Metlin metabolomics database (24,768 compounds); and the Forensic Toxicology Database by Agilent Technologies (7,509 compounds). Empirical formula for unidentified compounds was determined using the Find Formula function in the software package.

\section{Statistical analysis}

Data are expressed as the mean \pm SEM of at least three independent experiments.

\section{RESULTS}

\section{Liquid extraction yields and qualitative phytochemical screening}

Extraction of $1 \mathrm{~g}$ of dried $T$. lanceolata berry or leaf with various solvents yielded dried plant extracts ranging from $9 \mathrm{mg}$ (leaf hexane extract) to $171 \mathrm{mg}$ (berry methanolic extract) (Table 1). Deionised water and methanol gave relatively high yields of dried extracted material for both berry and leaf, whilst all other solvents extracted substantially lower masses. The dried extracts were resuspended in $10 \mathrm{ml}$ of deionised water (containing 1\% DMSO) resulting in the extract concentrations shown in Table 1.

Qualitative phytochemical studies (Table 1) showed that methanol and water extracted the widest range of phytochemicals. Both showed high levels of phenolics (both water soluble and insoluble phenolics) and flavonoids for both berry and leaf. Moderate to high levels of saponins were also seen in the methanolic and aqueous extracts, with higher levels

Table 1: The mass of dried extracted material, the concentration of extracts after resuspension in deionised water and qualitative phytochemical screenings of $T$. lancelotata berry and leaf extractions

\begin{tabular}{|c|c|c|c|c|c|c|c|c|c|c|c|c|c|c|c|c|}
\hline & 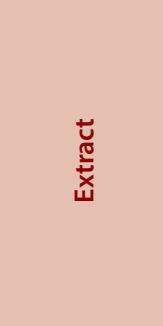 & 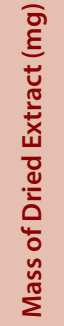 & 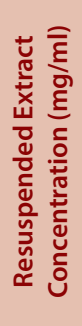 & 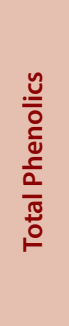 & $\begin{array}{l}\frac{0}{0} \\
\frac{0}{3} \\
\text { v } \\
\frac{1}{ \pm} \\
\frac{\pi}{3}\end{array}$ & 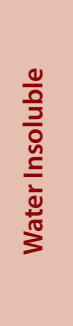 & 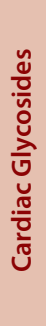 & 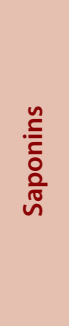 & 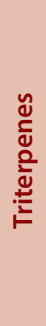 & $\begin{array}{l}\frac{n}{0} \\
\frac{0}{0} \\
\frac{0}{ \pm} \\
\frac{\Delta}{0} \\
\frac{0}{0}\end{array}$ & 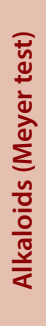 & 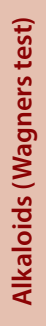 & $\begin{array}{l}\frac{n}{0} \\
\frac{0}{0} \\
\frac{c}{\pi} \\
\frac{\pi}{\square}\end{array}$ & $\frac{n}{\frac{n}{c}}$ & 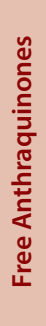 & 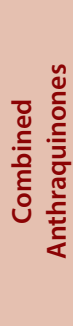 \\
\hline \multirow{5}{*}{ D. } & Methanol & 171 & 17.1 & +++ & +++ & +++ & - & ++ & + & - & - & - & +++ & - & - & - \\
\hline & Water & 111 & 11.1 & +++ & +++ & +++ & - & - & - & - & - & - & +++ & - & - & - \\
\hline & Ethyl Acetate & 56.7 & 5.7 & + & + & ++ & - & + & ++ & - & - & - & ++ & - & - & - \\
\hline & Chloroform & 47.2 & 4.7 & + & + & + & - & - & - & - & - & - & - & - & & \\
\hline & Hexane & 11 & 1.1 & - & - & - & - & - & - & - & - & - & - & - & & \\
\hline \multirow{5}{*}{ 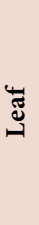 } & Methanol & 144 & 14.4 & +++ & +++ & +++ & - & +++ & + & - & - & - & +++ & - & - & - \\
\hline & Water & 134 & 13.4 & +++ & +++ & +++ & - & ++ & - & - & - & - & +++ & - & - & - \\
\hline & Ethyl Acetate & 17 & 1.7 & + & + & ++ & - & - & + & - & - & - & ++ & - & - & - \\
\hline & Chloroform & 37 & 3.7 & + & - & + & - & - & - & - & - & - & - & - & - & - \\
\hline & Hexane & 9 & 0.9 & - & - & - & - & - & - & - & - & - & - & - & - & - \\
\hline
\end{tabular}

+++ indicates a large response; ++ indicates a moderate response; + indicates a minor response; - indicates no response in the assay. 
Table 2: The T. lanceolata berry and leaf extract concentractions which inhibit $50 \%$ of G. duodenalis growth (IC ${ }_{50}$ ) $(\mu \mathrm{g} / \mathrm{mL})$ or induce $50 \%$ mortality in the Artemia nauplii bioassay $\left(\mathrm{LC}_{50}\right.$ values) $(\mu \mathrm{g} / \mathrm{mL})$

\begin{tabular}{|c|c|c|c|c|c|c|c|c|c|c|}
\hline & \multicolumn{5}{|c|}{ Berry } & \multicolumn{5}{|c|}{ Leaf } \\
\hline & 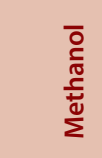 & $\begin{array}{l}\frac{ \pm}{ \pm ! n} \\
3\end{array}$ & 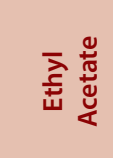 & $\begin{array}{l}\varepsilon \\
\frac{5}{0} \\
\frac{0}{0} \\
\frac{0}{c}\end{array}$ & 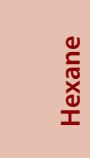 & 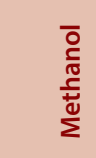 & 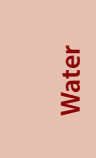 & 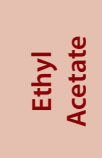 & $\begin{array}{l}\xi \\
\text { 흠 } \\
\text { 흔 }\end{array}$ & \\
\hline $\begin{array}{c}\mathrm{IC}_{50}(\mu \mathrm{g} / \mathrm{mL}) \text { against } G . \\
\text { duodenalis }\end{array}$ & 183.7 & 467.9 & 553.7 & 1180 & CND & 421.6 & 630.8 & 803 & CND & CND \\
\hline $\begin{array}{c}\mathrm{LC}_{50}(\mu \mathrm{g} / \mathrm{mL}) \text { in Artemia } \\
\text { nauplii assay }\end{array}$ & 3496 & 2140 & - & - & - & - & - & - & - & - \\
\hline
\end{tabular}

Numbers indicate the mean $\mathrm{IC}_{50}$ and $\mathrm{LC}_{50}$ values of triplicate determinations. $\mathrm{CND}=$ could not be determined as the $\%$ inhibition did not reach $50 \%$ at any concentration tested; -indicates that an $\mathrm{LC}_{50}$ could not be determined as the \% mortality did not exceed $50 \%$ at any concentration tested.

Table 3: Putative identification of compounds in the $T$. lanceolata berry extracts

\begin{tabular}{|c|c|c|c|c|c|}
\hline \multirow{2}{*}{ Putative Identification } & \multirow{2}{*}{ Empirical Formula } & \multirow{2}{*}{ Molecular Mass } & \multirow{2}{*}{$\begin{array}{l}\text { Retention } \\
\text { Time (mins) }\end{array}$} & \multicolumn{2}{|c|}{ Detection Mode } \\
\hline & & & & Positive & Negative \\
\hline \multirow{3}{*}{ 7-hydroxy-5-heptynoic acid } & $\mathrm{C}_{3} \mathrm{H}_{9} \mathrm{~N} \mathrm{~S}_{2}$ & 123.0174 & 0.842 & $\mathrm{X}$ & \\
\hline & $\mathrm{C}_{7} \mathrm{H}_{10} \mathrm{O}_{3}$ & 142.0619 & 0.842 & $\mathrm{X}$ & \\
\hline & $\mathrm{C}_{6} \mathrm{H}_{14} \mathrm{O}_{4}$ & 150.0892 & 2.351 & $\mathrm{X}$ & \\
\hline glucose & $\mathrm{C}_{6} \mathrm{H}_{12} \mathrm{O}_{6}$ & 180.0633 & 1.713 & $\mathrm{X}$ & $\mathrm{X}$ \\
\hline quinic acid & $\mathrm{C}_{7} \mathrm{H}_{12} \mathrm{O}_{6}$ & 192.0629 & 1.775 & & $\mathrm{X}$ \\
\hline Butibufen & $\mathrm{C}_{14} \mathrm{H}_{20} \mathrm{O}_{2}$ & 220.1462 & 10.933 & & $\mathrm{X}$ \\
\hline Cyclohexyl(1-hydroxycyclopentyl)acetic acid & $\mathrm{C}_{13} \mathrm{H}_{22} \mathrm{O}_{3}$ & 226.1566 & 10.074 & $\mathrm{X}$ & $\mathrm{X}$ \\
\hline polygodial & $\mathrm{C}_{15} \mathrm{H}_{22} \mathrm{O}_{2}$ & 234.1628 & 7.768 & $\mathrm{X}$ & $\mathrm{X}$ \\
\hline capsidiol & $\mathrm{C}_{15} \mathrm{H}_{24} \mathrm{O}_{2}$ & 236.1779 & 5.949 & $\mathrm{X}$ & \\
\hline Thiram & $\mathrm{C}_{6} \mathrm{H}_{12} \mathrm{~N}_{2} \mathrm{~S}_{4}$ & 239.9893 & 0.906 & $\mathrm{X}$ & $\mathrm{X}$ \\
\hline 3,3'-(2-Oxo-1,1-cyclohexanediyl)dipropanoic acid & $\mathrm{C}_{12} \mathrm{H}_{18} \mathrm{O}_{5}$ & 242.1136 & 1.917 & $\mathrm{X}$ & \\
\hline salutarisolide & $\mathrm{C}_{15} \mathrm{H}_{20} \mathrm{O}_{3}$ & 248.1416 & 7.969 & $\mathrm{X}$ & $\mathrm{X}$ \\
\hline CITRININ & $\mathrm{C}_{13} \mathrm{H}_{14} \mathrm{O}_{5}$ & 250.0842 & 4.728 & & $\mathrm{X}$ \\
\hline Desmethylmianserin & $\mathrm{C}_{17} \mathrm{H}_{18} \mathrm{~N}_{2}$ & 250.1502 & 8.396 & & $\mathrm{X}$ \\
\hline 3-(1-adamantyl)-2-oxopropyl acetate & $\mathrm{C}_{15} \mathrm{H}_{22} \mathrm{O}_{3}$ & 250.1534 & 9.061 & $\mathrm{X}$ & $\mathrm{X}$ \\
\hline PUNCTAPORIN B & $\mathrm{C}_{15} \mathrm{H}_{24} \mathrm{O}_{3}$ & 252.1719 & 8.524 & $\mathrm{X}$ & $\mathrm{X}$ \\
\hline Gamma-Glu-Leu & $\mathrm{C}_{11} \mathrm{H}_{20} \mathrm{~N}_{2} \mathrm{O}_{5}$ & 260.1391 & 10.558 & $\mathrm{X}$ & \\
\hline abscisic acid & $\mathrm{C}_{15} \mathrm{H}_{20} \mathrm{O}_{4}$ & 264.1357 & 8.958 & $\mathrm{X}$ & $\mathrm{X}$ \\
\hline $\begin{array}{l}\text { 5-(4-hydroxy-2,5-dimethylphenoxy)-2,2-dimethyl- } \\
\text { Pentanoic acid (Gemfibrozil M1) }\end{array}$ & $\mathrm{C}_{15} \mathrm{H}_{22} \mathrm{O}_{4}$ & 266.1497 & 9.192 & $\mathrm{X}$ & $\mathrm{X}$ \\
\hline \multirow[t]{2}{*}{$\begin{array}{l}\text { 8-Butyl-5,6-dihydrobenzo[f]quinazoline-1,3- } \\
\text { diamine }\end{array}$} & $\mathrm{C}_{16} \mathrm{H}_{20} \mathrm{~N}_{4}$ & 268.1666 & 8.663 & $\mathrm{X}$ & $\mathrm{X}$ \\
\hline & $\mathrm{C}_{15} \mathrm{H}_{27} \mathrm{NO}_{3}$ & 269.1996 & 8.51 & $\mathrm{X}$ & \\
\hline Lauroylsarcosine & $\mathrm{C}_{15} \mathrm{H}_{29} \mathrm{NO}_{3}$ & 271.2151 & 7.396 & $\mathrm{X}$ & \\
\hline cyclandelate & $\mathrm{C}_{17} \mathrm{H}_{24} \mathrm{O}_{3}$ & 276.1629 & 7.865 & $\mathrm{X}$ & \\
\hline $\begin{array}{l}\text { Benzenepropanoic acid, 4-[2-hydroxy-3-[(1- } \\
\text { methylethyl)amino]propoxy]- (Esmolol acid) }\end{array}$ & $\mathrm{C}_{15} \mathrm{H}_{23} \mathrm{NO}_{4}$ & 281.1633 & 9.717 & $\mathrm{X}$ & \\
\hline Gallic acid, 2-ethylhexyl ester isomer 2 & $\mathrm{C}_{15} \mathrm{H}_{22} \mathrm{O}_{5}$ & 282.1461 & 7.459 & & $\mathrm{X}$ \\
\hline Gallic acid, 2-ethylhexyl ester isomer 3 & $\mathrm{C}_{15} \mathrm{H}_{22} \mathrm{O}_{5}$ & 282.1462 & 5.305 & & $\mathrm{X}$ \\
\hline Dihydroartemisinin & $\mathrm{C}_{15} \mathrm{H}_{24} \mathrm{O}_{5}$ & 284.1605 & 8.31 & $\mathrm{X}$ & $\mathrm{X}$ \\
\hline $\begin{array}{l}\mathrm{N} \text {-(2,3-Dimethylphenyl)-1,3,5-triazaspiro[5.5] } \\
\text { undeca-1,4-diene-2,4-diamine }\end{array}$ & $\mathrm{C}_{16} \mathrm{H}_{23} \mathrm{~N}_{5}$ & 285.1948 & 8.842 & $\mathrm{X}$ & \\
\hline Glu Phe & $\mathrm{C}_{14} \mathrm{H}_{18} \mathrm{~N}_{2} \mathrm{O}_{5}$ & 294.1216 & 11.7 & $\mathrm{X}$ & \\
\hline gingerol & $\mathrm{C}_{17} \mathrm{H}_{26} \mathrm{O}_{4}$ & 294.1807 & 6.376 & $\mathrm{X}$ & \\
\hline Vomitoxin & $\mathrm{C}_{15} \mathrm{H}_{20} \mathrm{O}_{6}$ & 296.1259 & 11.018 & $\mathrm{X}$ & $\mathrm{X}$ \\
\hline
\end{tabular}




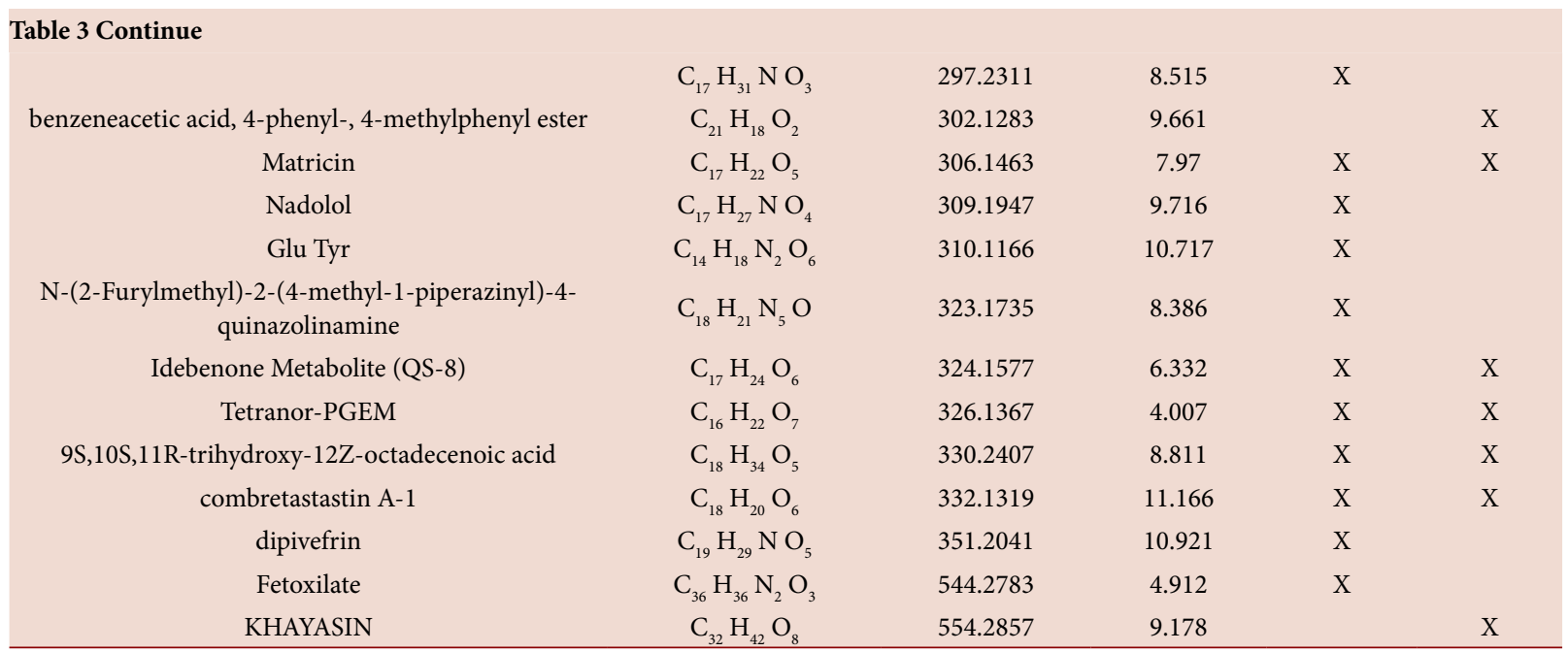

Only compounds detected in all berry extracts by high accuracy QTOF LC-MS are shown.

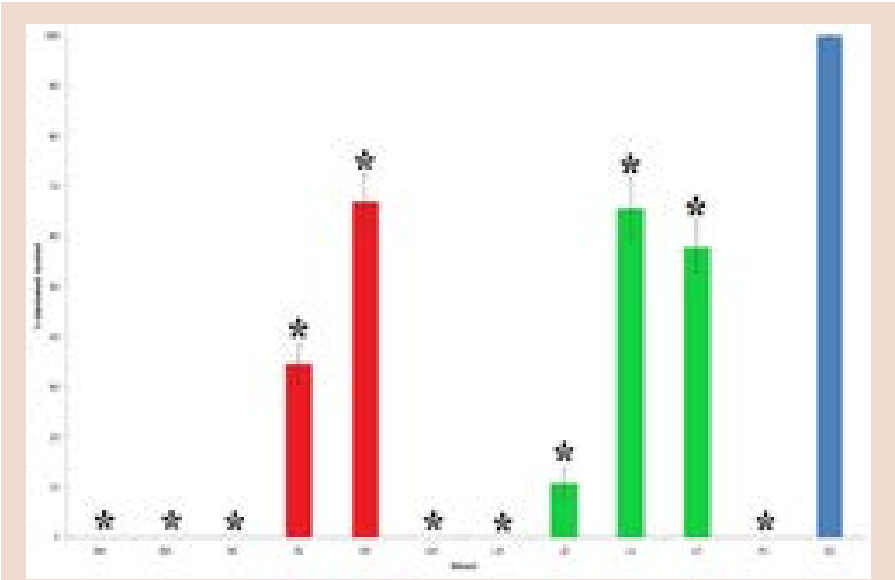

Figure 1: Inhibitory activity of $T$. lanceolata berry and leaf extracts against Giardia duodenalis trophozoites measured as a percentage the untreated control. $\mathrm{B}=$ =berry; $\mathrm{L}=$ =eaf; $\mathrm{M}=$ methanolic extract; $\mathrm{W}=$ water extract; $\mathrm{E}=$ =ethyl acetate extract; $\mathrm{C}=$ chloroform extract; $\mathrm{H}=$ hexane extract; $\mathrm{PC}=$ metronidazole control $(50 \mu \mathrm{g} / \mathrm{ml}) ; \mathrm{NC}=$ negative control. Results are expressed as mean \pm SEM of at least triplicate determinations. ${ }^{*}$ indicates results that are significantly different $(p<0.01)$ to the untreated control $(\mathrm{NC})$.

evident in the leaf extracts than in the berry extracts. Low to moderate levels of triterpenes were also detected in the methanolic (but not in the aqueous extracts) of both berry and leaf. No other phytochemical classes were detected in the methanolic and aqueous extracts. The ethyl acetate extracts also had low to moderate levels of phenolics and triterpenes. Low levels of phenolics were detected in the chloroform extract whilst no phytochemical class was present in detectable levels in the hexane extract.

\section{Inhibition of Giardia duodenalis proliferation}

T. lanceolata berry and leaf extracts were screened for their ability to inhibit Giardia duodenalis growth (Figure 1). All extracts displayed significant inhibitory activity. The methanolic and aqueous extracts of both berry and leaf, and the berry ethyl acetate extract, were particularly potent, each inhibiting $100 \%$ of the Giardial growth (compared to the untreated control). Furthermore, these extracts were extremely rapid in producing their inhibitory activity, with $100 \%$ inhibition seen in less than $5 \mathrm{~min}$ of exposure (unpublished results). The leaf ethyl acetate extract also significantly inhibited trophozoite growth (to approximately $11 \%$ of the growth of the negative controls).

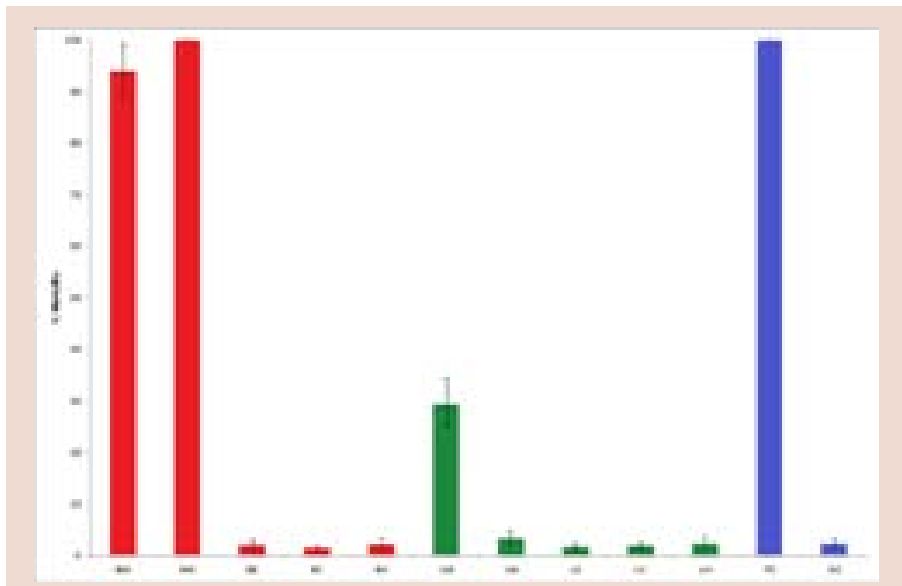

Figure 2: The lethality of $T$. lanceolata berry (red) and leaf (green) extracts $(1000 \mu \mathrm{g} / \mathrm{ml})$ and potassium dichromate control $(1000 \mu \mathrm{g} / \mathrm{ml})$ towards Artemia franciscana nauplii after $24 \mathrm{~h}$ exposure. BM=berry methanolic extract; $\mathrm{BW}=$ berry water extract; $\mathrm{BE}=$ berry ethyl acetate extract; $\mathrm{BC}=$ berry chloroform extract; $\mathrm{BH}=$ berry hexane extract; $\mathrm{LM}=$ leaf methanolic extract; $\mathrm{LW}=$ leaf water extract; $\mathrm{LE}=$ leaf ethyl acetate extract; $\mathrm{LC}=$ leaf chloroform extract; $\mathrm{LH}=$ leaf hexane extract; $\mathrm{PC}=$ potassium dichromate control; $N C=$ negative (seawater) control. Results are expressed as mean \pm SEM of at least triplicate determinations.

The inhibitory $T$. lanceolata extracts were further tested over a range of concentrations to determine the $\mathrm{IC}_{50}$ values (Table 2) for each extract against $G$. duodenalis. The methanolic berry extract was a particularly good inhibitor of $G$. duodenalis proliferation, with an $\mathrm{IC}_{50}$ of $183.7 \mu \mathrm{g} /$ $\mathrm{ml}$. The aqueous and ethyl acetate berry extracts also displayed good anti-giardial activity (approximately 470 and $550 \mu \mathrm{g} / \mathrm{ml}$ respectively). The leaf methanolic, aqueous and ethyl acetate extracts were also potent inhibitors of $G$. duodenalis proliferation, with $\mathrm{IC}_{50}$ values of approximately 420, 630 and $800 \mu \mathrm{g} / \mathrm{mL}$ respectively. We were unable to determine $\mathrm{IC}_{50}$ values for the berry hexane extract or for the leaf chloroform and hexane extracts as the levels of inhibition did not exceed $50 \%$ at any concentration tested.

\section{Quantification of toxicity}

T. lanceolata berry and leaf extracts were initially screened at $2000 \mu \mathrm{g} / \mathrm{ml}$ in the assay (Figure 2). For comparison, the reference toxin potassium 


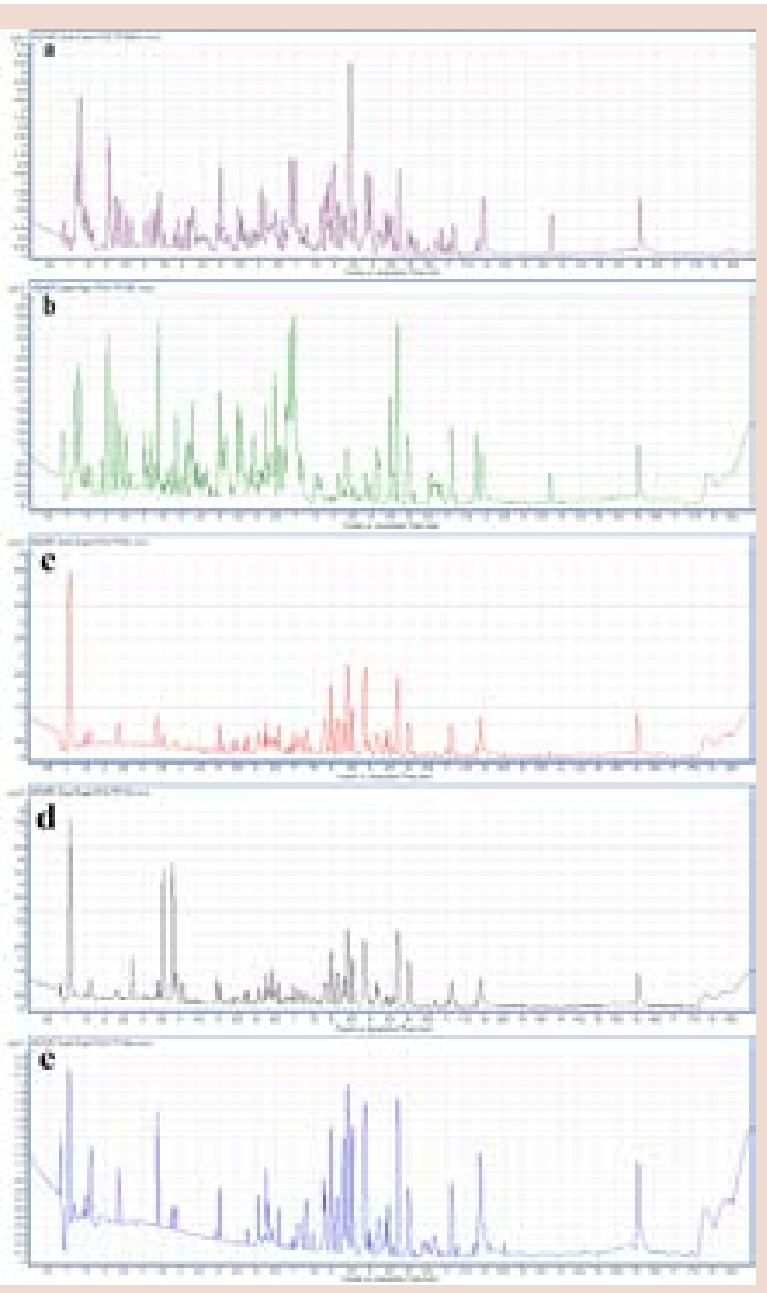

Figure 3: Positive ion RP-HPLC base peak chromatograms (BPC) of $2 \mu \mathrm{l}$ injections of T. lanceolata berry (a) methanolic, (b) aqueous, (c) ethyl acetate, (d) chloroform and (e) hexane extracts.

dichromate $(1000 \mu \mathrm{g} / \mathrm{ml})$ was also tested in the bioassay. The potassium dichromate reference toxin was rapid in its onset of mortality, inducing mortality within the first $3 \mathrm{~h}$ of exposure and $100 \%$ mortality was evident following 4-5 h (unpublished results). The berry methanolic and aqueous extracts also induced significant mortality following $24 \mathrm{~h}$ exposure, indicating that they were toxic at the concentration tested. The berry ethyl acetate, chloroform and hexane extracts did not induce mortality significantly different to the seawater control and were therefore deemed to be nontoxic. The leaf extracts generally induced lower levels of mortality in the Artemia nauplii than did the corresponding berry extracts. Indeed, the methanolic extract was the only leaf extract to induce mortality significantly above that of the seawater control, albeit with a mortality substantially below $50 \%$. Thus all of the leaf extracts were deemed to be nontoxic. To further quantify the effect of toxin concentration on the induction of mortality, the extracts were serially diluted in artificial seawater to testacross a range of concentrations in the Artemia nauplii bioassay at $24 \mathrm{~h}$. Table 2 shows the $\mathrm{LC}_{50}$ values of the T. lanceolata berry and leaf extracts towards $A$. franciscana. No $\mathrm{LC}_{50}$ values are reported for any of the leaf extracts or the berry ethyl acetate, chloroform and hexane extracts as less than $50 \%$ mortality was seen for all concentrations tested. Extracts with an $\mathrm{LC}_{50}$ greater than $1000 \mu \mathrm{g} / \mathrm{ml}$ towards Artemia nauplii have been defined as being nontoxic in this assay. ${ }^{24}$ As none of the extracts had a $\mathrm{LC}_{50}<1000 \mu \mathrm{g} / \mathrm{ml}$, all were considered nontoxic.

\section{HPLC-MS/MS analysis}

As the T. lanceolata berry extracts all displayed anti-Giardial activity, they were further examined by high accuracy HPLC-MS QTOF. The individual extract compound profiles were subsequently compared to identify any compounds that were common across these extracts as this has previously been shown to be an effective method of narrowing the focus of compounds responsible for a bioactivity ${ }^{21}$ The resultant total compound positive ion chromatograms are presented in Figure 3a-3e.

The T. lanceolata berry methanolic (Figure 3a) and aqueous extract (Figure $3 b$ ) positive ion base peak chromatogram revealed multiple overlapping peaks, particularly in the early stages of the chromatogram corresponding to the elution of polar compounds. Most of the extracted compounds had eluted in the first $10 \mathrm{~min}$, corresponding to $5-25 \%$ acetonitrile. Indeed, many of the peaks eluted in the first 5 min during the isocratic stage of the chromatogram ( $5 \%$ acetonitrile). However, the presence of several prominent peaks between 10 and 16.5 min indicates the broad spread of polarities of the compounds in this extract. The ethyl acetate (Figure 3c), chloroform (Figure 3d) and hexane extracts (Figure $3 \mathrm{e}$ ) are characterised by fewer peaks than evident in the methanolic and aqueous extracts, and a shift towards a great percentage of the compounds eluting at higher acetonitrile \%'s.

\section{Qualitative mass spectral analysis of T. lanceolata berry extracts}

In total, 998 unique mass signals were noted across the five T. lanceolata berry extracts (results not shown). Of these, 45 mass signals were present in all of the berry extracts which had anti-Giardial activity. Putative empirical formulas were achieved for all of these compounds. Of the 45 unique molecular mass signals detected across these extracts, 40 compounds (89\%) were putatively identified by comparison to the Metlin metabolomics, forensic toxicology (Agilent) and phytochemicals (developed in this laboratory) databases (Table 3). Their structures are shown in Figure 4.

\section{DISCUSSION}

Recent studies have highlighted the potential of plant medicines and have demonstrated that some plant components are very effective inhibitors of $G$. duodenalis growth, with similar potency to the gold standard drug metronidazole. ${ }^{14}$ Our studies demonstrates that T. lanceolata berry and leaf extracts also possess significant $G$. duodenalis growth inhibitory activity. The berry extracts were particularly potent, with $\mathrm{IC}_{50}$ values of approximately 180 and $470 \mu \mathrm{g} / \mathrm{mL}$ for the methanolic and aqueous extracts respectively. Also noteworthy was the rapid action of these extracts, with both the methanolic and aqueous extracts blocking $100 \%$ of $G$. duodenalis growth within 5 min of exposure. Furthermore, all T. lanceolata extracts were nontoxic in the Artemia nauplii bioassay, further demonstrating their suitability for chemotherapeutic treatment and prophylactic prevention of giardiasis.

Whilst all T. lanceolata extracts tested demonstrated Giardial antiproliferative activity, the berry extracts displayed higher potency and were therefore chosen for non-biased metabolomic comparison studies. The phytochemical composition of all T. lanceolata berry extracts was determined and compared to identify compounds common between extracts with $G$. duodenalis growth inhibitory activity. Similar metabolomics comparison studies have previously been used very successfully to narrow the focus of phytochemicals and allow for the identification of bioactive components in extracts from other plant species. In a recent study examining the anti-viral activity of Scaevola spinescens, a comparison of the metabolomic profiles of solvents of varying polarities was able to highlight 2 compounds from 239 detected mass signals as possibly 


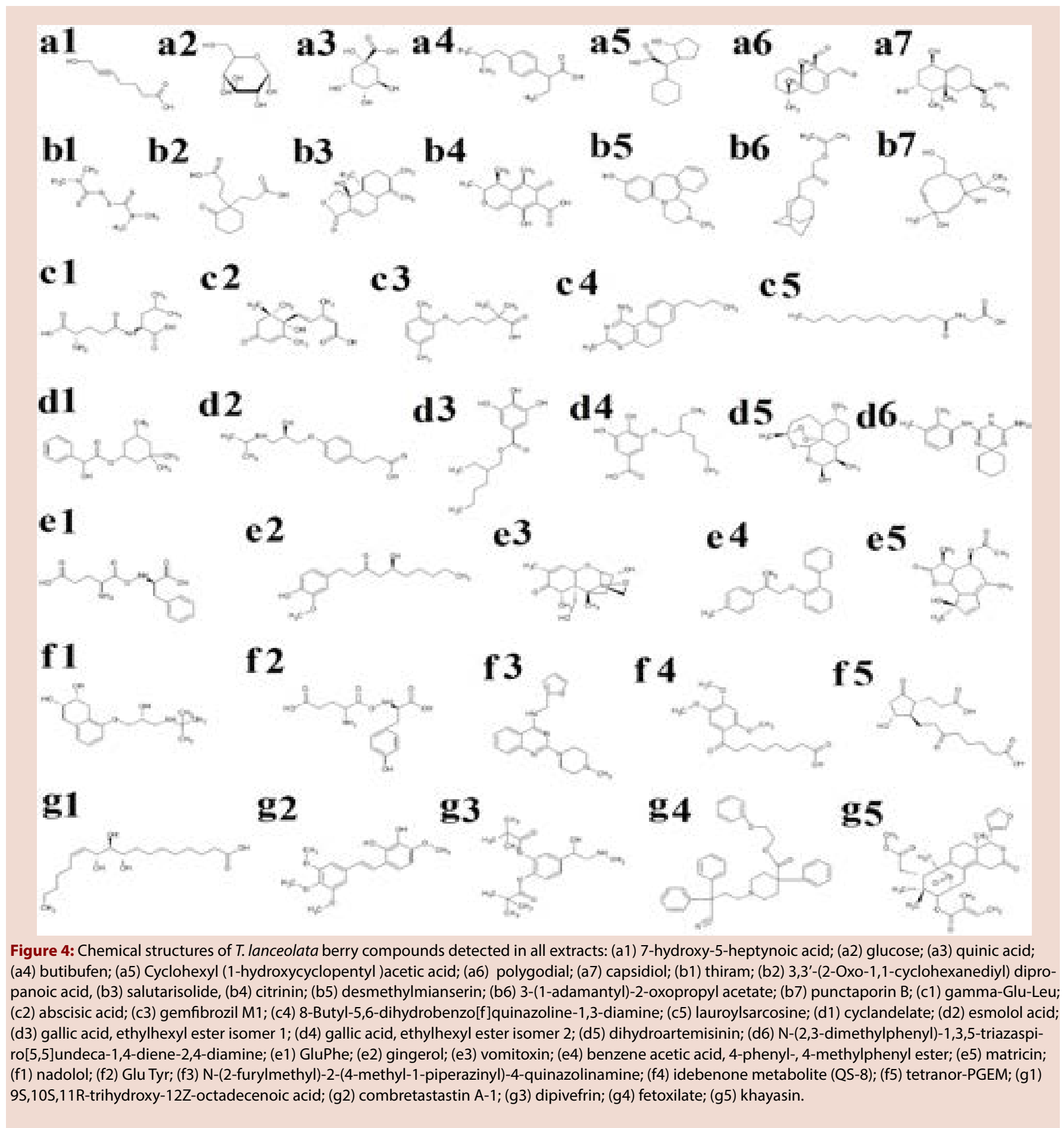

contributing to this activity. ${ }^{25}$ Of these 2 compounds, 1 had been previously been reported to have anti-viral activity, validating this approach.

High accuracy QTOF HPLC-MS was used to examine the metabolomics profiles of the various $T$. lanceolata berry extracts in our study. Liquid chromatography-mass spectroscopy (LC-MS) is a good choice for the analysis of compounds of a wide variety of compounds, particularly those of medium and high polarity. Coupling LC with high mass accuracy spectroscopy techniques using both mild ionisation and electrospray ionisation (ESI) can generate large amounts of useful information for compound identification and metabolomic analysis. Using these methods, molecular ions can be detected and their empirical formulas accurately determined and compared to databases. Furthermore, coupling this with ESI analysis also allows for the detection and characterisation of characteristic fragments, allowing for rapid identification of unknown compounds in a crude extract.

A number of interesting compounds were putatively identified in all T. Lanceolata berry extracts. Interestingly, the drimane-type sesquiterpene dialdehyde polygodial (Figure 4a6) was detected in all berry extracts. Several previous reports have reported polygodial as a major T. lanceolata component responsible for the flavour and aroma characteristics of this species. ${ }^{15}$ Indeed, it has been reported that polygoidal may account for nearly $40 \%$ of commercial T. lanceolata essential oil components. ${ }^{15}$ Many 
studies have reported the therapeutic properties of this compound, including its anti-bacterial, ${ }^{26}$ anti-fungal, ${ }^{27-29}$ anti-hyperalgesia, ${ }^{30}$ anti-inflammatory, anti-allergic and vasorelaxation activities. ${ }^{31}$ Several studies have also reported protozoal growth inhibitory activity for polygodial and its derivatives. Potent growth inhibition was reported for polygodial isolated from Drimysbra siliensis against Leishmania spp. and Trypanoso macruzi, with minimum inhibitory polygodial concentrations as low as $2 \mu \mathrm{g} / \mathrm{mL} .^{32}$ The same study also reported the induction of significant intracellular structural changes including mitochondrial swelling, loss of microtubule organisation and membrane damage following exposure to polygodial. Interestingly, these changes were extremely rapid, being apparent in $<15 \mathrm{~min}$ (compared to $>240 \mathrm{~min}$ for furazolidone which was used as a control drug in that study). This is consistent with our study, which showed significant Giardial death in less than $5 \mathrm{~min}$. Another study also reported potent anti-Leishmanicidal activity for several polygodial derivatives as well as anti-malarial activity against Plasmodium falciparum. ${ }^{33}$ We were unable to find similar reports of Giardial growth inhibitory activity for polygoidal. However, the inhibitory activity against other protozoal parasites indicates that polygodial may be responsible, at least in part, for the Giardial growth inhibition reported here.

Other structurally similar sesquiterpenoids were also putatively identified in the T. lanceolata extracts. Of particular interest, salutarolide (Figure 4b3) was present in all inhibitory $T$. lanceolata berry extracts. Salutarolide has been linked with anti-parasitic activity in multiple plants. In particular, plants of the genus Warburgia are known to have significant levels of salutarolide ${ }^{34}$ and several Warburgia spp. have been reported to have anti-parasitic activities. Warburgi augandensis hexane extracts inhibit Leishmania major and Leishmania donovani invitro, with IC50 values of $<10 \mu \mathrm{g} / \mathrm{mL} .{ }^{35}$ Similarly, Warburgia salutaris aqueous and methanolic extracts were reported to have anti-leishmanial activity, albeit with a higher $\mathrm{IC}_{50}$ values $(>1 \mathrm{mg} / \mathrm{mL})$. W. salutaris has also been reported to have anthelmintic activity against Haemonchus contortus. ${ }^{36}$

All extracts also contained a relative abundance of different isomeric forms of the gallotannin components ethyl hexyl gallic acid esters (Figure $4 \mathrm{~d} 3$ and Figure $4 \mathrm{~d} 4$ ). Gallotannins have been reported to inhibit the growth of a broad spectrum of microbial species ${ }^{37}$ through a variety of mechanisms including binding cell surface molecules including lipotoichoic acid and proline-rich cell surface proteins, ${ }^{38,39}$ and by inhibiting glucosyltransferase enzymes ${ }^{40}$ Whilst we were unable to find similar studies reporting inhibitory effects of tannins on Giardia spp. growth, a number of studies have reported high tannin contents in a variety of plants used in traditional medicine to treat giardiasis. ${ }^{41}$ Furthermore, tannins extracted from other plant species inhibit the growth of other protozoa including Schistoso mamansoni (the parasite responsible for schistosoma). ${ }^{42}$

The stilbene combretastatin A1 (Figure 4g2) was also putatively identified in all T. lanceolata berry extracts. Combretastatins are well known for their potent ability to block cancer cell progression and induce apoptosis by binding intracellular tublin, thereby disrupting microtubule formation. ${ }^{43}$ Whilst we were unable to find reports of the anti-Giardial activity of combretastatin A1, it acts in a similar to that of colchicine (N-[(7S)-1,2,3,10-tetramethoxy-9-oxo-5,6,7,9-tetrahydrobenzo[a]heptlen-7-yl] acetamide) by binding the colchicines binding site in tubulin. ${ }^{44}$ Thus, it is likely that combretastatin A1 may have anti-proliferative activity by blocking mitosis and thus blocking Giardial replication.

Several of the remaining compounds putatively identified in all inhibitory extracts contain lactone moieties. These include dihydroartemisin (Figure 4d5), vomitoxin (Figure 4e3), matricin (Figure 4e5) andkhayasin (Figure $4 \mathrm{~g} 5$ ). This is aninteresting finding as many of the current chemotherapeutic drugs used to treat giardiasis are lactone containing compounds, particularly lactone substituted nitroimidazoles (eg. metronidazole, secnidazole, tinidazole, ornidazole and albendazole). It has been suggested that compounds containing a lactone moiety may block the Giardial lipid deacylation/reacylation pathways. ${ }^{45}$ As Giardia spp. are unable to synthesise lipids by de novo pathways, they use host gastrointestinal precursor lipids for the synthesis of membrane and cellular lipids by deacylation/reacylation reactions. ${ }^{45}$ Thus, it is likely that lactone containing compounds may contribute to the inhibition of G. duodenalis growth by the blockage of lipid synthesis and metabolism pathways.

Quinic acid (Figure 4a3) was also identified in all T. lanceolata berry extracts. Recent studies have reported that substituted quinic acid compounds block leucyl-tRNA synthase activity in G. duodenalis. ${ }^{46}$ Aminoacyl-tRNA synthases are essential for translation of the genetic code by attaching the correct amino acid to each tRNA. Thus, blockage of leucyl-tRNA synthase activity would result in ineffective Leu-tRNA production and thus the inhibition of protein synthesis. We were unable to find reports of non-substituted quinic acid having the same activity. However, if subsequent testing confirms this activity, it is possible that quinic acid may also contribute to the anti-giradial activity T. lanceolata berry extracts. We were unable to find reports of Giardia spp. growth inhibitory activity for any of the other compounds putatively identified in the inhibitory T. lanceolata berry extracts. However, it is possible that these may also contribute to the anti-giardial activity reported here.

\section{CONCLUSION}

The lack of toxicity and effective G. duodenalis growth inhibitory activity of the T. lanceolata berry and leaf extracts demonstrate their potential as therapeutic agents for the treatment of giardisis.

\section{ACKNOWLEDGEMENTS}

Financial support for this work was provided by the Environmental Futures Research Institute and the School of Natural Sciences, Griffith University, Australia.

\section{CONFLICT OF INTEREST}

The authors have no conflicts of interest.

\section{ABBREVIATION USED}

DMSO: Dimethyl sulfoxide; $\mathbf{I C}_{50}$ : The concentration required to achieve $50 \%$ of the maximal effect; $\mathbf{L C}_{50}$ : The concentration required to achieve $50 \%$ mortality.

\section{REFERENCES}

1. Rahman MM, Hossain MA, Paul SK. Detection of Giardia lamblia and Cryptosporidium parvum by direct immunofluorescence assay in stool specimen. Mymensingh Med J. 2014;23(3):426-9.

2. Esch KJ, Petersen CA. Transmission and epidemiology of zoonotic protozoal diseases of companion animals. Clin Microbiol Rev. 2003;26(1):58-85.

3. Al-Delaimy AK, Al-Mekhlafi HM, Nasr NA. Epidemiology of intestinal polyparasitism among Orang Asli school children in rural Malaysia. PLoS Negl Trop Dis. 2014;8(8):e3074. doi: 10.1371/journal.pntd.0003074.

4. McDonnell PA, Scott KGE, Teoh DA. Giardia duodenalis trophozoites isolated from a parrot (Cacatua galerita) colonize the small intestinal tracts of domestic kittens and lambs. Vet Parasitol. 2003;11(1):31-46.

5. Thompson RC. Giardisis as an re-emerging infectious disease and its zoonotic potential. Int J Parasitol. 2000;30(12):1259-67.

6. Harris J, Plummer S, Lloyd D. Anti-giardial drugs. Appl Microbiol Biotechnol. 2001;57(5-6):614-9.

7. Upcroft JA, Dunn LA, Wright JM. 5-Nitroimidazole drugs effective against metronidazole-resistant Trichomonas vaginalis and Giardia duodenalis. Anti-microb Agents Chemother. 2006;50(1):344-7.

8. Upcroft P, Upcroft JA. Drug targets and mechanisms of resistance in the anaerobic protozoa. Clinical Microbiology Reviews. 2001;14(1):150-64.

9. Granados CE, Reveiz L, Uribe LG. Drugs for treating giardiasis. Cochrane Data- 
base Syst Rev. 2012;12. doi:10.1002/14651858.CD007787.pub2.

10. Christiaens TCM, Digranes A, Baerheim A. The relationship between sale of anti-microbial drugs and anti-biotic resistance in uropathogens in general practice. Scand J Prim Health Care. 2002;20(1):45-9.

11. Li LD, LiWC, Liu CW. Giardia intestinalis: effects of Pulsatilla chinensis extracts on trophozoites. Parasitol Res. 2012;111(5):1929-35.

12. Machado M, Dinis AM, Salgueiro L. Anti-Giardia activity of Syzygium aromaticum essential oil and eugenol: Effects on growth, viability, adherence and ultrastructure. Exp Parasitol. 2011;127(4):732-9.

13. Machado M, Dinis AM, Salgueiro L. Anti-Giardia activity of phenolic-rich essential oils: effects of Thymbracapitata, Origanumvirens, Thymus zygis subsp. sylvestris, and Lippiagraveolens on trophozoites growth, viability, adherence, and ultrastructure. Parasitol Res. 2010;106(5):1205-15.

14. Rayan P, Stenzel D, McDonnell PA. The effects of saturated fatty acids on Giardia duodenalis trophozoites in vitro. Parasitol Res. 2005:97(3):191-200.

15. Cock IE. The phytochemistry and chemotherapeutic potential of Tasmannia lanceolata (Tasmanian pepper): A review. Pharmacog Commn. 2013;3(4):13-25.

16. Cock IE. Medicinal and aromatic plants-Australia, in Ethnopharmacology section, Biological, Physiological and Health Sciences, Encyclopedia of Life Support Systems (EOLSS), Developed under the Auspices of the UNESCO, EOLSS Publishers, Oxford, UK, (http://www.eolss.net).; 2011.

17. LeStrange R. A history of herbal plants. Angus and Robertson; 1977.

18. Netzel M, Netzel G, Tian Q. Native Australian fruits-a novel source of antioxidants for food. Innov Food Sci Emerg Tech. 2007;8(3):339-46.

19. Winnett $\mathrm{V}$, Boyer $\mathrm{H}$, Sirdaarta J, et al. The potential of Tasmannia lanceolata as a natural preservative and medicinal agent: anti-microbial activity and toxicity. Pharmacog Commn. 2014;4(1):42-52.

20. Hart C, llanko P, Sirdaarta J, et al. Tasmannia stipitata as a functional food/natural preservative: anti-microbial activity and toxicity. Pharmacog Commn. 2014;4(4): 33-47.

21. Arkhipov A, Sirdaarta J, Rayan $P$, et al. An examination of the anti-bacterial, antifungal, anti-Giardial and anti-cancer properties of Kigelia africana fruit extracts. Pharmacog Commn. 2014;4(3):62-76.

22. Jamieson N, Sirdaarta J, Cock IE. The anti-proliferative properties of Australian plants with high anti-oxidant capacities against cancer cell lines. Pharmacog Commn. 2014;4(4):71-82.

23. Kalt FR, Cock IE. GC-MS analysis of bioactive Petalostigma extracts: Toxicity, antibacterial and anti-viral activities. Pharmacog Mag. 2014;10(37 Suppl):S37-48.

24. Cock IE, Ruebhart DR. Comparison of the brine shrimp nauplii bioassay and the ToxScreen-II test for the detection of toxicity associated with Aloe vera (Aloe barbadensis Miller) leaf extract. Pharmacog Res. 2009;1(2):102-8.

25. Cock IE, Matthews B. Metabolomic profiling of anti-viral Scaevola spinescens extracts by high resolution tandem mass spectroscopy. Acta Hort in press; 2014.

26. Kubo I, Fujita K, Lee SH. Anti-bacterial activity of polygoidal. Phytother Res. 2005;19(12):1013-7.

27. De Almeida Alves TM, Ribeiro FL, Kloos H. Polygoidal, the fungitoxic component from the Brazilian medicinal plant Polygonum punctatum. Mem Inst Owwaldo Cruz. 2001;96(6):831-3.

28. Lee SH, Lee JR, Lunde CS. In vitro anti-fungal susceptibilities of Candida albicans and other fungal pathogens to polygodial, a drimane sesquiterpene dialdehyde. Planta Med. 1999;65(1):204-8

29. Taniguchi M, Adachi T, Oi S. Structure-activity relationship of the Warburgia sesquiterpene dialdehydes. Agric Biol Chem. 1984;48(1):73-8.

30. Mendes GL, Santos ARS, Campos MM. Anti-hyperalgesic properties of the extract and of the main sesquiterpene polygodial isolated from the barks of Drymiswinteri (Winteraceae). Life Sci. 1998;63(5):369-81.

31. Da Cunha FM, Frode TS, Mendes GL. Additional evidence for the anti-inflammatory and anti-allergic properties of the sesquiterpene polygodial. Life Sci. 2001;70(2):159-69.

32. Corrêa DS, Tempone AG, Reimão JQ. Anti-leishmanial and anti-trypanosamal potential of polygodial isolated from stem barks of Drimysbra siliensis Miers (Winteraceae). Parasitology Research. 2011;109(1): 231-6.

33. Claudino VD, Silva KCD, Cechinel F. Drimanes from Drimysbra siliensis with leishmanicidal and anti-malarial activity. Memórias do Instituto Oswaldo Cruz. 2013;108(2):140-4

34. Maroyi A. The genus Warburgia: A review of its traditional uses and pharmacology Pharm Biol. 2014;52(3):378-91.

35. Ngure PK, Tonui WK, Ingonga J. In vitro anti-leishmanial activity of extracts of Warburgia ugandensis (Canellaceae), a Kenyan medicinal plant. J Med Plant Res. 2009;3(2):61-6.

36. Ahmed M, Laing MD, Nsahlai IV. (2012). In vitro anthelmintic activity of crude extracts of selected medicinal plants against Haemonchus contortus from sheep. J Helminthol. 2013;87(4):174-9.

37. Buzzini P, Arapitsas P, Goretti M. Anti-microbial activity of hydrolysable tannins Mini Rev Med Chem. 2008;8(12):1179-87.

38. Wolinsky LE, Sote EO. Isolation of natural plaque-inhibiting substances from Nigerian chewing sticks. Caries Res. 1984;18(3):216-25.

39. Hogg SD, Embery G. Blood-group-reactive glycoprotein from human saliva interacts with lipoteichoic acid on the surface of Streptococcus sanguis cells. Arch Oral Biol. 1982;27(3):261-8

40. Wu-Yuan CD, Chen CY, Wu RT. Gallotannins inhibit growth, water-soluble glucan synthesis, and aggregation of Streptococci mutans. J Dent Res. 1988;67(1):51-5

41. Tapia-Perez MAE, Tapia-Contreras A, Cedillo-Rivera R. Screening of Mexican medicinal plants for anti-protozoal activity-Part II. Pharm Biol. 2003;41(3):180-3

42. Abozeid K, Shohayeb M, Ismael A. In vitro tests for efficacy of tannins extracted from pomegranate (Punica granatum) against Schistoso mamansoni miracidia. J Sci Technol. 2012;13:531-8.

43. Dark GG, Hill SA, Prise VE. Combretastatin A-4, an agent that displays potent and selective toxicity towards tumor vasculature. Cancer Res. 1997;57(10):1829-34.

44. Bhardwaj S, Bakshi S, Chopra B. Synthesis of combretastatin analogues with their potent anti-cancer activity. Int J Res Pharm Sci. 2010;1(4):414-6.

45. Das S, Castillo C, Stevens T. Phospholipid remodeling/generation in Giardia: the role of the Lands cycle. Trends Parasitol. 2001;1(7):316-9.

46. Zhang $\mathrm{YH}$, Xue MQ, Bai YC. 3, 5-Dicaffeoylquinic acid isolated from Artemisia argyi and its ester derivatives exert anti-Leucyl-tRNA synthetase of Giardia lamblia (GI-LeuRS) and potential anti-giardial effects. Fitoterapia. 2012;83(7):1281-5.

\section{PICTORIAL ABSTRACT}
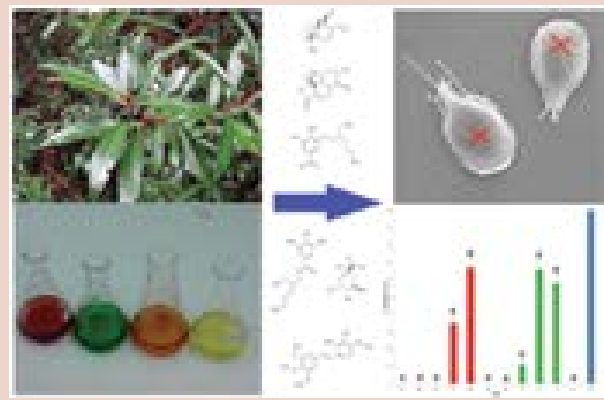

\section{SUMMARY}

- Tasmanian pepper (T. lanceolata) berry and leaf extracts are potent inhibitors of Giardia growth.

- All Tasmanian pepper extracts were nontoxic in the Artemia fransiscana bioassay.

- HPLC-QTOF MS analysis putatively identified 40 compounds in all inhibitory extracts.

- Based on the compound identifications, a pleuripotent anti-giardisis mechanism is proposed.

\section{ABOUT AUTHOR}

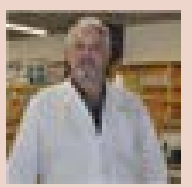

Dr lan Cock: Leads a research team in the Environmental Futures Research Institute and the School of Natural Sciences at Griffith University, Australia. His research involves bioactivity and phytochemical studies into a variety of plant species of both Australian and international origin including Aloe vera, South Asian and South American tropical fruits, as well as Australia plants including Scaevola spinescens, Pittosporum phylliraeoides, Terminalia ferdinandiana (Kakadu plum), Australian Acacias, Syzygiums, Petalostigmas and Xanthorrhoea johnsonii (grass trees). This range of projects has resulted in nearly 200 scientific publications in a variety of peer reviewed journals. 